\title{
A POLÍTICA EXTERNA DO GOVERNO LULA: ASPIRAÇÕES E DIFICULDADES
}

Shiguenoli Miyamoto*

\section{Introdução}

Dos oito anos do governo de Luiz Inácio Lula da Silva

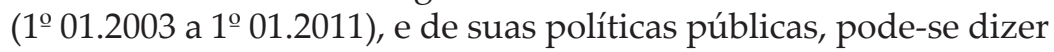
tudo, menos que foram monótonos. Uma delas, a política externa, segundo os críticos e a oposição ao governo, nada mais foi do que controversa e ruidosa. ${ }^{1}$ Na perspectiva de outros, como o ex-chanceler Celso Amorim (1ํㅜ 01.2011) e os demais co-responsáveis pela condução da mesma, a política externa foi ativa e altiva. ${ }^{2}$

Tirando-se os possíveis exageros de ambas as partes, poderíamos afirmar que essas designações certamente não fazem

* Livre-Docente e Professor Titular em Relações Internacionais e Política Comparada, do Departamento de Ciência Política da Unicamp. A produção deste texto contou com recursos do Conselho Nacional de Desenvolvimento Científico e Tecnológico ( $\mathrm{CNPq})$, através de Bolsa de Produtividade em Pesquisa (1B) concedida ao autor.

${ }^{1}$ Discordâncias com relação à política externa do governo Lula podem ser encontradas em: COSTA, Paulo Gouvêa da (coord.) (2009) - A política externa do Brasil - Presente e futuro. Brasília: Democratas-Diretório Nacional/ Senado Federal.

${ }^{2}$ Conferir a versão oficial em: http://www.itamaraty.gov.br/temas/balancode-politica-externa-2003-2010. Acesso em 15 de abril de 2011. 
$|120|$

A política externa do governo Lula...

justiça, nem correspondem à realidade da política desempenhada pelo Brasil no cenário mundial.

Nessas interpretações teríamos que ponderar a existência de um viés que atrapalha qualquer análise sobre a política externa brasileira, uma vez que nelas observamos o discurso de atores diretamente interessados e/ou envolvidos no processo. São, portanto, abordagens militantes, comprometidas.

A primeira das ressalvas, antes mesmo de começar o governo de Lula, em 2003, foi a constatação da existência de diversos personagens diretamente vinculados à formulação e implementação da política externa, além do próprio ex-presidente da República.

De um lado, o auxiliar maior do ex-presidente, nessa área, representado pelo recém indicado chanceler Celso Amorim, agora em sua segunda passagem pelo Ministério das Relações Exteriores. ${ }^{3}$ A segunda figura era o secretário geral, embaixador Samuel Pinheiro Guimarães. Por último, Marco Aurélio Garcia, muito próximo a Lula, desde o início dos anos 80, e secretário de Relações Internacionais do Partido dos Trabalhadores, agora na função de Assessor Especial de Relações Internacionais da Presidência da República, com acesso direto à mesma.

Possuidores de estilos diferentes trouxeram inquietações, durante apreciável tempo, sobre o grau de competência e esfera de atuação de cada um, principalmente o novo assessor, desempenhando papel bastante distinto dos que o anteciparam no cargo.

A segunda dificuldade foi entender as diretrizes da política externa, se identificadas ou coincidentes com as propostas durante anos pregadas pelo partido que elegeu o presidente, ou se essas apenas foram utilizadas como promessas durante

\footnotetext{
${ }^{3} \mathrm{O}$ mesmo cargo já fora ocupado pelo ministro, entre 20 de julho de 1993 e $1^{\circ}$ de janeiro de 1995, no governo de Itamar Franco (02.10.1992 a $1^{\circ}$ 01.1995).
} 
a campanha eleitoral e seriam, portanto, simplesmente relegadas, descartadas ao longo do tempo. ${ }^{4}$

Em outro plano, pelo menos três fatos poderiam ser mencionados, e que marcaram o início da gestão do governo no cenário internacional. O primeiro, a viagem do assessor presidencial à Venezuela, com a finalidade de ajudar a resolver graves problemas que afetavam a economia daquele país.

Isso poderia ser interpretado como elemento inovador e norteador dos rumos da política externa, privilegiando parceiros com os quais, os agora donos do poder, se identificavam no campo político e ideológico.

O segundo, a declaração do ex-ministro da Ciência e Tecnologia, Roberto Amaral, na primeira semana após a posse de Lula, defendendo a possibilidade de o Brasil desenvolver tecnologia nuclear com finalidades bélicas.

O terceiro fato a ser recuperado foi a visita inaugural do ex-presidente ao exterior, ou seja, rumando para a Argentina, dando a entender que o grande vizinho do Sul mereceria importância especial na pauta da política externa brasileira.

Isoladamente, fatos dessa natureza, respeitando as devidas conjunturas, já se tinham verificado em períodos anteriores, respectivamente, nos governos de Jânio da Silva Quadros (31.01.1961 a 25.08.1961) e João Belchior Marques Goulart (08.09.1961 a $1^{\text {o }}$ 04.1964), no de Ernesto Geisel (15.03.1974 a 15.03.1979), e mesmo no de Fernando Henrique Cardoso

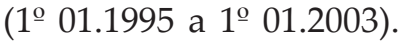

No conjunto, entretanto, a política externa vinha carregada de interrogações, inclusive sobre a conduta do país nas

\footnotetext{
${ }^{4}$ Uma abordagem que discute esse problema pode ser encontrada em PRADO, Lídia Domingues Peixoto (2007) - A política externa do primeiro governo Lula (2003-2006). Dissertação de Mestrado apresentada ao Programa de Pós-Graduação em Relações Internacionais Unesp Unicamp-PUC/SP, digitalizada. Acesso em 20 de junho de 2011. http://www.santiagodantassp.locaweb.com.br/br/arquivos/defesas/ LidiaPrado.pdf.
} 
|122 |

A política externa do governo Lula...

negociações econômicas, no cumprimento das obrigações assumidas pelo governo anterior, na (re)definição das parcerias tradicionais, e nas instâncias multilaterais.

Semelhante ao movimento browniano, a política externa brasileira ziguezagueou como um besouro, durante todo o governo Lula, procurando aos poucos definir melhor suas demandas e estabelecer metas gerais.

Agiu buscando tirar proveito da conjuntura internacional, para alavancar sua inserção no jogo mundial do poder, ainda que muitas vezes de forma ambígua, deixando margens a dúvidas sobre sua competência e credibilidade.

São alguns desses problemas, enfrentados pelo país na condução de sua política externa, que serão objeto de reflexão no presente texto.

\section{As demandas no limiar do século}

Certamente não foi por falta de viagens e discursos das autoridades brasileiras, que o país não atingiu o patamar desejado no cenário internacional, como se apregoava. A importância das viagens foi sempre ressaltada pelo ex-presidente Lula, em visível demonstração de que ele próprio, como timoneiro-mor, deveria colocar-se na linha de frente.

Com essa atitude, o chefe de Estado conduziria a diplomacia e os negócios brasileiros, na defesa dos interesses nacionais, mostrando ao mundo que, a partir de seu governo, o país deveria finalmente passar a ser respeitado, condição que, até então, se entendia como inexistente.

Por isso, o périplo internacional feito pelo ex-presidente se multiplicou, carregando em seu entorno ministros e empresários, em busca de novas alternativas, e ampliando as antigas, carreando recursos e investimentos, vendendo produtos e serviços.

Estaria, dessa forma, desempenhando ativo papel, dando ao Estado nova feição, aquilo que Richard Rosecrance, na década 
de 80, chamava de Estado empresário, no contexto que Ronaldo Sardenberg alguns anos antes já designara como globalização. ${ }^{5}$

Como se veria, posteriormente, esse último conceito, no fechar do século $X X$, com as devidas mudanças de entendimento sobre o mesmo, passaria a influenciar de forma acentuada as análises sobre relações internacionais e a maneira como cada país, aqui incluindo o Brasil, deveria se posicionar no mundo.

É dentro deste quadro de rápidas transformações, que o Brasil passou a formular suas demandas, procurando compatibilizar discurso e ação. Mas, conforme o governo Lula, as diretrizes não poderiam ser as mesmas dos períodos anteriores.

Longe disso, segundo o entendimento dos novos agentes do poder, a denominada política neoliberal não mais faria parte da agenda e do vocabulário governamentais. Daí as diferentes escolhas tanto na definição dos novos parceiros, quanto das metas e prioridades a serem atingidas, pensadas agora sob outras lentes.

Ativa e altiva seriam, portanto, as duas faces da moeda, as marcas que deveriam, a partir daquele momento, caracterizar a conduta brasileira no plano internacional. Atuação em frentes diversas, sem se curvar às pressões e exigências das grandes potências e das agências multilaterais, seria, destarte, a base sobre a qual se sustentaria a política do Estado brasileiro para ocupar e ampliar suas influências no mundo, escapando do entorno geográfico sul-americano.

${ }^{5}$ Cf. ROSECRANCE, Richard (1986) - The rise of the trading State. Commerce and conquest in the Modern World. New York: Basic Books; SARDENBERG, Ronaldo (1982) - Estudo das Relações Internacionais. Curso de Relações Internacionais. Unidade IV. Brasília: Editora Universidade de Brasília. Para este, "no presente estudo, o conceito de sistema será utilizado de forma metafórica, para simbolizar o processo de globalização que caracteriza a política internacional do século $X X$, pois desde a incorporação à esfera colonial dos últimos territórios "não civilizados" da África, no final do século passado (XIX), o universo diplomático passou a ser um só e a estender-se por todo o planeta". p. 29. 
| 124 |

A política externa do governo Lula...

Sem deixar de lado, mesmo porque não poderia fazê-lo, o relacionamento com as nações do Hemisfério Sul seria privilegiado, na tentativa de, conjuntamente, mudar os caminhos da geopolítica mundial.

Assim, a América do Sul converteu-se em seu espaço principal de operação hemisférica, na busca pela liderança regional. Muitas vezes vigorosamente defendida em discursos presidenciais, essa terminologia aos poucos foi sendo excluída do vocabulário brasileiro, motivada pela forte reação dos vizinhos, contrariados com a pretensão do Palácio do Planalto. ${ }^{6}$

No mesmo nível geográfico, abaixo do Equador, a África igualmente recebeu atenção, com o ex-presidente Lula tendo visitado 29 países durante seus dois mandatos, enquanto o ex-chanceler Amorim passou pelo continente em 60 oportunidades.

Nesse meio tempo, o Ministério das Relações Exteriores aumentou sua representação diplomática na África, abrindo 16 novas embaixadas. ${ }^{7}$ Houve alterações inclusive na estrutura administrativa do Itamaraty, tendo o Departamento de África e Oriente Médio (DAO) se desdobrado em duas repartições separadas, cada uma delas dedicada a essas regiões (DA e DOM).

\footnotetext{
${ }^{6}$ Esse tipo de discurso e as ações do governo brasileiro passaram a ser identificadas como imperialistas ou subimperialistas, relembrando o que ocorrera nos anos 70, com o projeto de Brasil Potência do governo de Emílio Garrastazu Médici (30.10.1969 a 15.03.1974). Uma leitura que explora essa nova faceta da política brasileira no continente pode ser encontrada em LUCE, Mathias Seibel (2007) - O subimperialismo brasileiro revisitado: a política de integração regional do governo Lula (2003-2007). Dissertação de Mestrado apresentada ao Programa de Pós-Graduação em Relações Internacionais do Instituto de Filosofia e Ciências Humanas da Universidade Federal do Rio Grande do Sul, IFCH/UFRGS digitalizada. Acesso em 20 de maio de 2011. http://www.dominiopublico.gov.br/ download/texto/cp061297.pdf.

${ }^{7}$ Durante os oito anos de seu governo, Lula abriu 68 representações diplomáticas, entre embaixadas e consulados, principalmente em países com pouca projeção mundial. Embora o intercâmbio com essas nações
} 
Países que usufruíam de condições semelhantes às brasileiras, passaram a jogar papel significativo, não apenas em termos bilaterais, mas também no plano das relações multilaterais em blocos outros como o constituído pela Índia, Brasil e África do Sul (IBAS) e por Brasil, Rússia e China (BRICs).

No âmbito mais geral dos grandes organismos internacionais, onde efetivamente se verifica a definição das regras da política global, o governo brasileiro procurou, sem sucesso, conquistar parcela maior de poder, em cargos diretivos de entidades como a Organização Mundial do Comércio (OMC), a Organização Internacional do Trabalho (OIT), o Banco Interamericano de Desenvolvimento (BID).

A reforma das grandes instituições, visando sua democratização, inclusive por considerar-se que a estrutura das mesmas não mais contempla a realidade do novo século, converteu-se em uma das obsessões da política brasileira. Daí a persistência na defesa sobre a necessidade de se ampliar o Conselho de Segurança da Organização das Nações Unidas, incorporando Estados com poder regional, entre os quais o próprio país, uma vez que o mesmo se enquadraria em tal categoria, ao lado de outros como a Índia e a África do Sul.

A tentativa de entrada no G8 e, na impossibilidade de ser arrombar a porta desse grupo como apregoava o ex-presidente, para conseguir seu intento, levou o Brasil a investir em alternativas como o G20.

Ênfase semelhante foi verificada dando sequência ao processo de cooperação regional, como a Iniciativa de Integração da Infra-Estrutura Regional Sul-Americana (IIRSA), do Mercado Comum do Sul (MERCOSUL), e de negociações desse bloco com o similar europeu. É bem verdade que, embora isso fosse verdadeiro na retórica, na prática o que se observou é que

seja reduzido, além das condições precárias de infraestrutura e de funcionamento, com pequeno número de diplomatas aí alocados pelo Itamaraty, os votos desses governos poderiam ajudar a atender as demandas brasileiras nos organismos multilaterais. 
| 126 |

A política externa do governo Lula...

o processo de integração regional caminhou bastante longe daquilo que permeava o discurso governamental.

Para conseguir ver atendidas suas reivindicações, medidas diversas foram implementadas. A remissão da dívida de países africanos e sul-americanos, o reconhecimento da República Popular da China como economia de mercado, investimentos realizados na América do Sul com recursos de agências de fomento nacional como o Banco Nacional de Desenvolvimento Econômico e Social (BNDES), do Banco do Brasil ou a promessa de criar em cada país vizinho uma representação do Instituto de Pesquisa Econômica Aplicada (IPEA), converteram-se em mecanismos para obter o apoio dos países beneficiados para que o Brasil pudesse eleger seus representantes nos organismos internacionais.

A Comunidade dos Países de Lingua Portuguesa (CPLP), pode ser também lembrada como instituto que mereceu olhares brasileiros, obtendo, dessa e de seus membros, apoio para que o país pudesse reivindicar lugar no CS/ONU, em oportunidades diversas em 2004, 2006, 2008 e 2010. Evidentemente, apesar da promessa da CPLP, a mesma jamais conseguiu se converter em certeza, uma vez que a reestruturação do CS/ONU nunca foi colocada de fato na mesa de negociações.

Missões de paz no Haiti, no continente africano ou no Timor Leste, transformaram-se em outros recursos utilizados para mostrar que o país não se encontrava interessado apenas em ver atendidas suas demandas particulares.

O Brasil procurava,com esse comportamento, e canalizando recursos para países em desenvolvimento, apresentar-se à comunidade internacional como nação adulta, portanto responsável, e preocupada em resolver pelo menos parte das grandes dificuldades que afetam parcela significativa da Humanidade, e que encontravam pouca receptividade por parte das grandes potências.

Por isso, defendeu propostas para atacar problemas como a fome mundial, as dificuldades enfrentadas pelos refugiados, e o uso do meio ambiente de forma sustentável, dando mostras de amadurecimento e necessidade de se olhar para as nações menos 
privilegiadas. Esse papel caberia aos grandes países, que deveriam esforçar-se para melhorar as condições sócio-econômicas dos pobres, e reduzir as diferenças entre os diversos membros da comunidade internacional.

Ao realizar propostas dessa natureza, o Brasil estaria mostrando ao mundo sua face de grande Estado. Longe de adotar comportamento egoísta, estaria, na realidade, buscando soluções para melhorar o funcionamento do próprio sistema internacional.

\section{Ambiguidades e desconfianças}

Com frentes abertas em múltiplas direções, o país não conseguiu ver contempladas suas demandas. Pelo menos no nível em que esperava e desejava. É bem verdade que, favorecido pela conjuntura internacional, o Brasil aumentou sua capacidade de negociação nas esferas mundiais. Prova disso, é que não apenas saldou seus compromissos financeiros com organismos como o Fundo Monetário Internacional (FMI), como também manteve-se em confortável situação durante todo o período considerado.

Alguns motivos poderiam ser encontrados, e que explicam razoavelmente o insucesso das reivindicações brasileiras. Em primeiro lugar, o país nunca conseguiu acumular capacidade suficiente para reverter, isoladamente, a seu favor, a situação mundial, mesmo quando os grandes países passaram (e continuam) por grave crise.

Em segundo lugar, o fato de ter adotado políticas direcionadas para os países do Hemisfério Sul, não trouxe consigo os resultados aguardados. As mesmas não se converteram em apoio efetivo em vários níveis.

De um lado, porque, mesmo com esforços conjugados em muitas oportunidades, isto não se mostrou condição suficiente para contrapor-se com sucesso ao poderio dos Estados do Norte.

De outro lado, porque nem sempre as demandas dos demais países em desenvolvimento coincidiram com as aspirações brasileira. Muitos deles se encontram localizados bastante próximos, e enfrentam dificuldades de ordem semelhante, mas 
| 128 |

A política externa do governo Lula...

encontram-se voltados ou preocupados com seus próprios problemas domésticos e regionais.

Em terceiro, os demais países, mesmo favorecidos pelo governo Lula - caso da República Popular da China, sendo reconhecida como economia de mercado - não se sintonizaram com as ambições brasileiras. Nesse caso, agiram como sempre fizeram, e nos mesmos moldes em que atua o próprio Brasil, ou seja, visando em primeiro lugar seus interesses imediatos ou de médio prazo, sob a égide de um pragmatismo que modela a atuação de todos os Estados nos negócios internacionais.

Vários outros motivos podem ser encontrados, e que dificultaram o atendimento das reivindicações brasileiras, impossibilitando sua ascensão internacional da forma desejada. No cenário sul-americano alguns deles não se referem exclusivamente ao governo de Lula, mas dizem respeito à própria dinâmica da disputa pela supremacia subcontinental, conforme a variação das conjunturas interna e regional, ainda que isto nunca seja explicitado.

É o caso, por exemplo, das divergências muitas vezes acentuadas entre os governos argentino e brasileiro, embora ambos se constituam nos parceiros maiores do MERCOSUL, portanto, responsáveis pelo bom funcionamento e pelo sucesso ou fracasso da entidade. As constantes dificuldades, que podem ser enumeradas às dezenas, encontradas no relacionamento bilateral e multilateral são bastante visíveis, sobretudo com as amplas reivindicações feitas pelo governo argentino, sob os mandatos de Ernesto e Cristina Kirchner, em diferentes momentos.

Falta de sintonia com outros Estados como a Bolívia, verificada com a ocupação das refinarias da Petrobrás, das reivindicações paraguaias para o aumento da tarifa de energia elétrica da barragem de Itaipu, a recusa do Equador em honrar seu compromisso com o Brasil para pagar a dívida, e mesmo, com as criticas de Hugo Chávez às instituições brasileiras, poderiam ser arroladas como fatores que, se não prejudicaram o relacionamento bilateral, também não ajudaram a facilitar 
o papel do Brasil como agente maior nesta parte do mundo, deixando-o em situação desconfortável em mais de uma oportunidade.

No contexto do continente americano, o modus operandi da diplomacia brasileira notadamente manteve distanciamento com a postura dos Estados Unidos bloqueando a possibilidade de formação da Associação de Livre Comércio das Américas (ALCA). Isto não contribuiu, entretanto, para que o relacionamento com a grande nação do Norte fosse contaminado ou considerado critico apesar de discordâncias outras como o problema dos protecionismos e em outras áreas. As freqüentes referências presidenciais a seu congênere, George W. Bush, tratando-o como "meu amigo" e a Barack Obama que o considerou o "grande cara", indicam o clima de amistosidade entre os governantes dos dois países.

$\mathrm{Na}$ América Central, mormente os vínculos com o governo de Cuba, a proximidade mantida pelo ex-presidente com os irmãos Castro era demonstrada sem qualquer constrangimento, porém identificada como problemática por organismos ligados aos direitos humanos.

A simpatia demonstrada não apenas com o regime cubano, mas fazendo o mesmo com a Venezuela, onde haveria, segundo Lula um "excesso de democracia", poderiam ser lembrados como fatores que pouco contribuíram para aumentar a credibilidade brasileira na defesa da democracia e dos direitos humanos.

Do mesmo jeito, a fórmula encontrada pelo governo brasileiro para enviar de volta imediatamente atletas cubanos que procuravam refugio em território brasileiro, e agindo de maneira distinta no caso de Cesare Battisti, cidadão italiano condenado em seu país e que entrou em território brasileiro portando documentos falsificados, gerou incontáveis críticas internas e externas.

Ressalvas igualmente se aplicam, em contexto mais amplo, aos casos da Síria, da Líbia e do Irã, alvos de pressão internacional, países com os quais Brasília tem interesses econômicos, além das próprias identificações pessoais mantidas pelo ex-presidente com 
| 130 |

A política externa do governo Lula...

mandatários daqueles locais. O clima amistoso mostrado pelo ex-presidente Lula com governantes desses países, serviu para deixar em dúvida, as orientações e as verdadeiras intenções do governo brasileiro.

Alie-se a esses fatos, declarações infelizes feitas em Cuzco, em 2007, quando se discutia a constituição da Comunidade Sul-Americana das Nações (CASA), e na África. Nesses exemplos, referiu-se de forma pejorativa, respectivamente, à origem dos ex-colonizadores das Américas, e às condições sócio-educacionais dos países de além-mar.

Situação difícil também seria verificada com a tentativa de expulsar o jornalista norte-americano Larry Rother que tecera comentários considerados ofensivos sobre a honra presidencial, ao escrever acerca do hábito presidencial de consumir bebidas alcoólicas.

Nesse caso, ainda que a imprensa nacional em inúmeras oportunidades já tivesse feito insinuações sobre o fato, o ex-presidente dava vazão ao autoritarismo e intolerância em receber críticas, alegando não aceitá-las de profissionais estrangeiros, baseados no Brasil, ainda que esses estivessem no exercício de sua atividade. ${ }^{8}$

\section{Considerações finais}

Oscilando entre as nações altamente industrializadas, os considerados emergentes e os países em desenvolvimento, o Brasil pareceu repetir, em parte, a antiga estratégia adotada pelos governos militares, de querer obter benefícios simultaneamente do Primeiro e do Terceiro Mundos.

\footnotetext{
${ }^{8}$ Desse jornalista, ver: ROHTER, Larry (2008) - Deu no New York Times O Brasil segundo a ótica de um repórter do jornal mais influente do mundo.Rio de Janeiro: Objetiva. Visão aguda sobre as viagens e comportamento presidenciais pode ser encontrada em SCOLESA, Eduardo \& NOSSA, Leonencio (2006) - Viagens com o Presidente: Dois repórteres no encalço de Lula do Planalto ao exterior. Rio de Janeiro: Record.
} 
Com os países desenvolvidos queria negociar em condições de igualdade, compartilhando as responsabilidades pelo destino do mundo. Mas ao mesmo tempo advogava melhores condições de negociação, colocando-se como agente e líder terceiro-mundista.

Mutatis mutandis, no limiar do século XXI, o Brasil procurou jogar em todos os campos. Com o Hemisfério Norte buscou estabelecer condições de igualdade nas negociações, reclamando dos protecionismos, acusando os países ricos pelos desequilíbrios sócio-econômicos verificados, criticando-os pelas falta de sensibilidade com os problemas globais.

Simultaneamente, desejou participar das instâncias de decisão como o G8, das direções dos principais organismos internacionais, principalmente reivindicando vaga como membro permanente do Conselho de Segurança da ONU.

Com os países em desenvolvimento procurou construir uma grande frente de oposição, capaz de contrapor-se aos interesses das grandes potências, mas junto às quais gostaria de sentar-se e tomar decisões.

Na companhia dos emergentes, quis abrir caminho para que todos, individual e coletivamente, pudessem ascender, dividindo as responsabilidades pelas políticas mundiais.

Para alavancar sua ascensão, adotou por vezes políticas ora mais agressivas, ora reticentes em áreas diversas que vão desde o relacionamento com a Argentina até a política dos direitos humanos.

Na política doméstica, com forte impacto externo, adotou medidas, procurando fortalecer as empresas brasileiras para competir com as estrangeiras, favorecendo sua internacionalização. Entre essas, os casos verificados com a Petrobrás, a Fiocruz, a Embrapa, além das grandes empreiteiras como Odebrecht, Camargo Correia, Andrade Gutierrez e Queiroz Galvão, cuja atuação se tornou cada vez mais forte no continente sul-americano, na África e no Oriente Médio.

Apesar do discurso de colaboração e integração no continente sul-americano, o que se observou é que, com exceção da Bolívia, o Brasil sempre se manteve superavitário nas trocas comerciais com seus vizinhos. 
| 132 |

A política externa do governo Lula...

Não exerceu o papel de liderança cobiçado, ainda que tenha mobilizado recursos para diversos vizinhos. Mas evitou problemas, por exemplo, para assumir responsabilidades em prol dos interesses regionais, ou mesmo em divergências verificadas em oportunidades distintas como na disputa uruguaio-argentino em torno das papeleras, quando se eximiu desse episódio, que envolveu dois membros do MERCOSUL.

Nos foros globais procurou manter-se atento, reivindicando, criticando, mas sabendo de suas capacidades limitadas. Enquanto isso se sucedia, o próprio ex-presidente participava simultaneamente de dois grandes eventos, ainda que os focos dos mesmos longe estivessem de coincidir, o primeiro nos encontros do Fórum Social Mundial e o segundo em Davos. Não é por acaso que acontecem em regiões cujo estágio de desenvolvimento são marcadamente distintos.

Em termos do acréscimo de seu poder nacional, para respaldar suas demandas, medidas foram propostas para a recuperação da capacidade militar, com a aquisição de equipamentos ou tentativas de modernização das três armas.

Estruturou-se melhor o documento de Política de Defesa Nacional em segunda versão de 2005, tendo o governo divulgado em dezembro de 2008 a Estratégia Nacional de Defesa. ${ }^{9}$ Esta última era uma grande carta de intenções sobre as novas realidades a serem enfrentadas pelo país em áreas sensíveis nas próximas décadas, abarcando a Amazônia, a tríplice fronteira no sul do continente, além das preocupações com a costa litorânea, principalmente por causa dos recursos naturais representados pelo pré-sal.

No limite, poder-se-ia dizer que o Brasil procurou forjar nova identidade internacional, distinta das anteriores, e que deveria servir como fator agregador para ampliar suas capacidades e ver-se respeitado no cenário global.

\footnotetext{
${ }^{9}$ Esses documentos podem ser obtidos na página do Ministério da Defesa. Cf. http://www.defesa.gov.br. Acesso em 26 de junho de 2011.
} 